\title{
Determinants of Policy Decisions for Non-Commercial Drivers with OSA: An Integrative Review
}

Dorrie Rizzo ${ }^{1,2}$, Eva Libman ${ }^{2,3}$, Laura Creti ${ }^{2,3}$, Marc Baltzan $^{3,4}$, Sally Bailes ${ }^{2,3}$, Catherine Fichten ${ }^{2,3,5}$, Gilles Lavigne ${ }^{1,6}$

${ }^{1}$ Université de Montréal, 2900 Edouard-Montpetit blvd., Montreal, QC Canada H3T 1J4

${ }^{2}$ Jewish General Hospital, 4333 Côte-Ste-Catherine rd., Montreal, QC Canada H3T 1E4

${ }^{3}$ McGill University, 845 Sherbrooke W., Montreal, QC Canada H3A OG4

${ }^{4}$ Mount Sinai Hospital, 5690 Cavendish blvd., Montreal, QC Canada H4W 1S7

${ }^{5}$ Dawson College, 3040 Sherbrooke W., Montreal, QC Canada H3Z 1A4

${ }^{6}$ Hôpital du Sacré-Cœur de Montréal, 5400 Gouin W., Montreal, QC Canada H4J 1C5

Address correspondence to:

Dorrie Rizzo, M.sc.

Jewish General Hospital

Department of Psychiatry

4333, Cote-Ste-Catherine rd., B-9

Montreal (Quebec) Canada H3T1E4

dorrie.rizzo@umontreal.ca 
(C) This manuscript version is made available under the CC-BY-NC-ND 4.0 license https://creativecommons.org/licenses/by-nc-nd/4.0/

Acknowledgements: The authors thank librarian Teodora Constantinescu for her guidance in the review aspects of this paper and the late Christiane Manzini, research project coordinator, for her wisdom and helpful suggestions during the preparation of this paper. The authors have no conflicts of interest to disclose. 


\section{Summary}

Excessive daytime sleepiness and reduced cognitive funcitioning secondary to obstructive sleep apnea (OSA) have been identified as an important health-related risk in commercial transportation with, possibly, an increased chance of road accidents. This has resulted in a variety of policies and restrictions imposed on commercial drivers. Here we review current knowledge to assess whether available data are sufficient to guide policy decisions concerning restrictions for non-commercial drivers. The review shows that there is a lack of uniformity among different consensus conferences and guidelines as to how to deal with drivers with OSA. Clear guidelines are limited and few are evidence based. It is unclear which aspect of OSA is the most valid measure of severity (e.g. Apnea-Hypopnea Index vs Oxygen Desaturation Index). Traditionally, sleepiness has been invoked as a major risk factor for impaired driving. Recently, there also has been an awareness that daytime fatigue, as distinct from sleepiness, has an impact on driving behaviour. However, the precise effect of fatigue on driving, as well as its role in the formulation of guidelines, remain to be evaluated. We conclude that there are at least two major difficulties for the driving recommendation process: (a) there is no accurate metric quantifying severity of driving risk associated with OSA, and (b) there are substantial individual differences among those with OSA, both experiential and behavioural. We present implications from this review for future research and policy formulation.

Key words: Obstructive sleep apnea; driving behavior; driving risk; guidelines; cognitive function; motor vehicle crashes; sleepiness; fatigue. 


\section{Introduction}

Obstructive sleep apnea (OSA) is common and often under-recognized in the general population. It affects up to $10 \%$ of the middle-aged population and potentially up to $50 \%$ of adults over age 60 (1-3). Symptoms of OSA are widespread and include cognitive dysfunction, depression, anxiety, memory problems and insomnia. Also related to OSA are health risks such as hypertension and obesity, or illnesses such as diabetes and cardiovascular disorders (4-8). Of particular relevance to driving, excessive daytime sleepiness secondary to OSA has been identified as an important health-related risk in commercial transportation (9-14) with, possibly, an increased chance of road accidents due to impairments in vigilance, concentration, memory, and executive function (15).

The objective of the present review is to summarize the state of knowledge about OSA and risk-related driving behaviour among noncommercial drivers. We will attempt to assess current limitations regarding sleep disorder and driving research (e.g. low ecological validity, unclear guidelines for non-commercial drivers with OSA) and present potential directions, including: identification of risky drivers, modification of risky driving behaviours and prediction of potentially dangerous driving circumstances. To this end, we will evaluate the current state of knowledge on driving policies for individuals with OSA and whether it is sufficient to guide policy decisions about non-commercial drivers who suffer from OSA. 
We will first describe the physiological and cognitive effects of OSA with a focus on potential consequences for neurocognitive and behavioural functioning that can be relevant for driving tasks and behaviours in non commercial drivers. This is followed by a section on the association of motor vehicle accidents and risk-related behaviors for drivers with OSA. The final section critically reviews how fitness to drive has been evaluated in OSA patients and the implications for future advances.

\section{What is OSA and why is it so important to diagnose?}

OSA is a serious sleep disorder characterized by recurrent episodes of partial or complete collapse of the upper airway during sleep and is associated with physiological changes and destabilisation of respiratory control (2). The reduction of airflow often leads to changes in gas exchange and recurrent arousals from sleep. This chronic condition is a severe risk factor for morbidity and mortality, mainly due to intermittent drops in blood oxygen saturation $(2,16,17)$. Intermittent hypoxia is reported to promote oxidative stress by increasing production of reactive oxygen species and angiogenesis, increasing sympathetic activation with blood pressure elevation, and both systemic and vascular inflammation with endothelial dysfunction. All these are variably related to risk of chronic morbidity and mortality in the form of cardiovascular disease, metabolic dysfunction, cognitive decline, and selected cancer progression (18-21).

When an apnea or hypopnea event is prolonged, the effort to restore breathing causes cortical arousal and consequent disruption of the sleep architecture and of its continuity $(17,22)$. Because OSA causes both hypoxia and sleep disruption, its impact is widespread, affecting multiple organs and regulatory systems (17). Untreated OSA can lead to high blood pressure, stroke, heart failure, diabetes, depression, and other serious health issues (23-32). Over time, repetitive hypoxia may lead to structural changes in the brain which maintain breathing instability during sleep $(17,18,22,33)$. 
Under normal circumstances, the majority of sensory outputs capable of modifying breathing are down-regulated at sleep onset. The control of breathing transitions to being predominantly chemical in which the level of carbon dioxide in the blood is a critical mediator for regulating ventilation (17). In the case of OSA, rapid return to arousal during an apnea event is essential to restore breathing. However, too frequent arousals during sleep create instability in respiratory control and may contribute to risk of sleepiness during wakefulness. The instability of breathing control also affects the systemic circulation and oxygen delivery. One study suggests that the structural changes in OSA may consist of a mixture of irreversible atrophy, cell death and non-lethal pathology (i.e. inflammation); this seems to contribute to central nervous system dysfunction as well as to psychological and physiologic comorbidities (34). More specifically, results showed abnormalities in metabolite ratios in frontal lobe white matter and in the hippocampus of individuals with severe OSA, compared to healthy controls (34). Although the metabolite concentrations were not significantly correlated with neurocognitive test results, significant correlations were found with the severity of OSA (34). Cognitive functioning (attention, reaction time, memory, executive function, mental status, visual function) is associated with driving outcome measures in studies measuring crash risk $(35,36)$.

\section{Potential physiological and cognitive effects of OSA- induced sleep and respiratory disruption}

It has been demonstrated that neurocognitive deficits occur with high frequency in OSA. These deficits can affect any cognitive domain, such as learning, memory, and attention and can increase the risk of dementia in older adults (37). One study found that slower reaction time, decreased brain activation in areas involved in arousal and attention, impaired response selection, motor response, and decision making were all significantly associated with the apnea/hypopnea index ( $\mathrm{AHI}$ ), but not with the oxygen desaturation index (SpO2) (38). These findings imply that it is the $\mathrm{AHI}$ and the neurological component of OSA that drives impaired performance rather than SPO2 levels. Another study on the 
cognitive profile of OSA reported that as compared with controls, patients with OSA have more lapses and/or increased reaction times in tasks requiring sustained attention, selective attention or vigilance (6). On the other hand, aspects of language were preserved and no specified deficit was found for psychomotor speed. This researcher suggests that vigilance and attention deficits could influence other cognitive aspects (e.g., executive function, episodic memory, psychomotor speed, fine motor coordination) (6).

Importantly, the previous study also noted that common comorbidities found in OSA patients (i.e. obesity, diabetes, hypertension, etc.) are known to be independently associated with cognitive deficits and may also contribute to the decline of neurocognitive function in OSA patients. Such observed associations highlight the complex interrelationship of systems and risk factors. Sleep disordered breathing, disrupted sleep, insulin resistance, psychological or physiological stress, obesity, and hypertension may all be implicated as risk factors for cognitive impairment. Cognitive deficits in patients with OSA have been well demonstrated, but the pathophysiology of these deficits is still controversial.

\section{OSA and Risk-Related Driving Behaviour in Non-Commercial Drivers}

There have been significant recent advances in understanding the role of OSA in non-commercial driving performance and in individuals with OSA and their related risk (e.g. (39-44)). Nevertheless, evidence-based recommendations remain a challenge (45). Motor vehicle crashes in noncommercial drivers are too few to support the need for expeditious diagnostic evaluations or removal of driving privileges (45, 46 ). Both the American Thoracic Society and the Canadian Thoracic Society have noted that there is no compelling evidence supporting the need to restrict driving privileges of patients with OSA $(47,48)$. This was based on the examination of current evidence, which is of moderate quality due to lack of definitive studies and limited accessibility to regional motor vehicle crash registries. 
Despite the lack of evidence, important policies are currently established around the world, influencing how health practitioners are to treat their patients with OSA. As summarized in Table 1, various research and policies have been developed, independently, in Australia, Belgium, Canada, France, and the U.S.A. Although these are among the leading countries in driving research, such policies have been built on the best evidence available at that time and most derive from consensus based on opinion and experience. It is to be noted that the European Union has issued a basic document that constitutes a minimum set of rules that every Member State needs to follow that were not included in Table 1 (49). These recommendations for non-commercial drivers focus on screening, assessment tools and treatment plans that are already considered by the listed national guidelines provided in Table 1.

\section{Current clinical guidelines and policies regarding OSA and driving}

\section{American Thoracic Society}

Clinical practice guidelines provided by the American Thoracic Society state that moderate to severe daytime sleepiness could be one indication of high-risk driving (50). This statement highlights the importance of assessing sleepiness in newly diagnosed OSA patients, whatever the level of OSA severity.

\section{Canadian Thoracic Society and Canadian Sleep Society}

These two societies published position papers which state that there are no clear clinical guidelines for non-commercial drivers and that assessment should be made on a case-by-case basis (47). Apnea/hypopnea Index, self-report sleepiness measures and objective daytime 
performance measures all show at best weak correlation with motor vehicle crash risk (47). The recommendation is that a qualified sleep specialist would be best able to assess driver risk related to OSA.

\section{Obstructive Sleep Apnoea Working Group}

In 2013, in Brussels, this group published the New Standards and Guidelines for Drivers with Obstructive Sleep Apnoea syndrome (51). Recommendations focus on commercial drivers and suggest periodic training sessions on OSA, physiology of sleep, vigilance, sleepiness at the wheel, and other related topics. The recommendations were based on information about the characteristics and risks of OSA and the association between OSA and (assumed) increased risk for motor vehicle crashes. These recommendations were primarily directed toward various interest groups (e.g. commercial drivers, employers of commercial drivers, medical professionals, road police departments and related personnel).

\section{Aerospace Medical Association}

Although not directly related to driving, a recent position paper on transportation related occupations argues that the associations between OSA, obesity and cognitive impairments are strong enough to recommend OSA screening of individuals who are morbidly obese (52). Based on commercial driver data, these researchers highly recommend such screening for the airplane pilots, with the goal of improving aviation safety.

Although some of the above-mentioned studies and recommendations were based on commercial drivers, they have had an influence on European and North-American policies related to non-commercial drivers, whose driving practices are quite different.

\section{OSA and motor vehicle crashes}


(c) This manuscript version is made available under the CC-BY-NC-ND 4.0 license https://creativecommons.org/licenses/by-nc-nd/4.0/

A survey covering 19 European countries collected self-reported sleep-related data that included driving behaviour, history of drowsy driving and accidents in non-commercial drivers. The data implicated self-reported drowsy driving as a major safety hazard. Individual determinants of falling asleep while driving were younger age, male gender, driving exposure, higher daytime sleepiness and high risk of OSA (53). Both American and Australian studies reported inattentiveness, fatigue and sleepiness as major contributors to police-reported motor vehicle crashes leading to death and injury $(54,55)$. A second Australian study supported the association between OSA and increased daytime sleepiness, and decreased vigilance, with a 2- to 7-fold increased risk of motor vehicle crashes. However, results from that study indicated that only $40 \%$ of subjects with OSA who were non-commercial drivers displayed impaired performance on a driving simulator task after provocation by sleep loss or alcohol (56).

Ward et al. (57) investigated whether the risk of motor vehicle car crashes was higher in patients with OSA than in the general community and, if so, the nature of the risk. Participants were recruited from a sleep research centre, prior to clinical and polysomnographic evaluation. Using polysomnography, driving simulation and questionnaires, the researchers evaluated relationships between self-reported near-misses and selfreported motor vehicle car crashes with OSA severity, degree of daytime sleepiness, and other potential risk factors. Results for 2,673 participants with OSA showed that: 1 ) subjects with untreated OSA (AHI > 5 events per hour) self-reported crashes at a rate three times higher (0.06 motor-vehicle crashes/year) than the healthy individuals (0.02 motor-vehicle crashes/year); 2 ) among the predominantly male, middleaged, and obese participants, $11 \%$ with OSA reported having a crash because they felt sleepy or fell asleep behind the wheel; 3 ) $26 \%$ of participants reported at least one near-miss due to sleepiness; and 4) $32 \%$ reported having fallen asleep behind the wheel. In addition, a strong overall association between sleepiness and increased rate of reported near-misses was found. 


\section{OSA, obesity, and motor vehicle crashes}

According to the World Health Organization, in $2014,13 \%$ of the world's adults were obese. OSA is estimated to affect over 100 million adults in the world. In 2007, a group of researchers stated that obesity is the most important risk factor for OSA and that it is estimated that $70 \%$ of patients with OSA are obese (58). An important study by Teràn-Santos et al. (59) showed a strong association between OSA (measured by AHI) and increased driving accidents among non-commercial drivers, after adjustment for potential cofounders such as body-mass index. However, the researchers did not evaluate whether obesity itself was a risk factor for road accidents. This was later addressed in a review by Kay and McLaughlin (60), who reported that obesity is associated with increased crash risk and increased risk of serious or fatal injury, but that treatment of OSA improved driving performance and reduced crash risk, independent of obesity. Given the high prevalence of OSA in obese individuals, the review highlights the likelihood of obese drivers falling asleep while driving or having impaired critical driving-related abilities such as reduced vigilance (i.e. attentional lapses measured by EEG) (61).

One relatively recent study found that obese individuals with OSA had a twofold higher risk of traffic accidents than healthy comparison individuals. Increased neck circumference and excessive daytime sleepiness were predictors of higher accident risk in non-commercial drivers with OSA (62). Another study did not find an association between BMI or hypoxemia and risk of near-miss or crash but did find an association between neck circumference, (another commonly used measure for obesity) and crash risk (63-65).

In a prospective study examining the association between obesity and cognition, Gunstad et al. (66) found that many obese patients showed impaired performance on cognitive testing before having bariatric surgery. Specifically, obese patients had cognition scores in the low average 
to average range as compared to normative test data. Data also showed that patients who underwent surgery had improved memory performance at 12 weeks of follow-up (within the average or above average range for all cognitive tests) while those who did not have the surgery had a decline in memory performance (67). Of relevant to driving, the obese patients who underwent bariatric surgery improved on attention, compared to obese patients who did not undergo the surgery. In addition, they reported that patients without hypertension who underwent bariatric surgery had better short delay recall at 12 weeks than those with hypertension (67). A systematic review by Sarkhosh et al.

(68) concluded that for obese patients with OSA, bariatric surgery improves or resolves OSA in a majority of such patients. The potential outcome of bariatric surgery is valuable as a proof of concept for demonstrating the effects of obesity on cognitive functioning.

A 2008, study proposed three key factors in the association between obesity and OSA: 1) obesity may narrow the airway resulting in the block of airflow, 2) higher leptin has an impact on the distribution of fat, and 3) obesity may also be a result of OSA (ex.: lack of energy) (69). These findings are supported in more recent systematic review which highlighted OSA as a disorder associated with morbidity (70). Obesity has been shown to be associated with subjective and objective sleepiness independent of sleep apnea (71). Daytime sleepiness and fatigue are frequent complaints among obese individuals, even among those who do not demonstrate OSA.

\section{OSA and driving behavior: Sleepiness and fatigue}

A recent important finding demonstrated considerable inter-individual variation in daytime sleepiness and neurobehavioral impairment among OSA patients (56). It was found that participants with and without OSA were significantly different on psychomotor vigilance tasks (mean auditory reaction time test, lapse frequency test). It was also shown that driving simulator performance varied widely among patients with OSA: 
$60 \%$ of OSA patients showed trait-like resistance to performance impairment in a driving simulation task when stressed with sleep restriction or alcohol. They were also able to sustain attention and steer normally to avoid crashes during a 90-minute simulated country drive (59). The researchers found that degree of impairment was not explained by OSA severity (i.e. AHI, hypoxemia, frequency of arousals), that many patients with OSA reported little or no daytime sleepiness, and that many individuals with OSA had driven for several years without incident (56). Paradoxically, the study also showed that some individuals with mild AHI were more affected by sleepiness.

Last year, the National Sleep Foundation published a consensus statement that healthy individuals who have slept for 2 hours or less in the preceding 24 hours are too impaired to operate a motor vehicle without risk of motor vehicle accidents (72). A Canadian study involving a random sample of commercial drivers revealed that chronic short sleep duration is a risk factor for neurobehavioral performance impairments, while the results for OSA were less clear (71). The study consistently showed that neurobehavioral performance has a differential susceptibility to the effects of sleep deprivation, and that the performance of some individuals is quite impacted by sleep deprivation whereas other subjects are relatively resistant. Recommendations were made to not only test commercial drivers for OSA, but to assess sleep durations among commercial drivers (71).

In addition to sleepiness, other behavioral aspects of OSA may include, as mentioned, neurocognitive deficits (vigilance, concentration, memory impairments, and executive function), psychological problems (anxiety, depression) and a history of driving accidents (15). However, people with OSA do not have a uniform pattern of sleepiness nor of neurocognitive deficits, and they are capable of some behavioural resilience (5).

Measuring the deficits in OSA remains a challenge because it is unclear whether oxygen desaturation (i.e. Sp0 ${ }_{2}$ levels) or sleep fragmentation (i.e. 
Apnea-Hypopnea Index or arousal index) is associated with cognitive dysfunction. Consequently, identifying a specific subgroup of individuals who are more resistant or vulnerable to cognitive deficits is also a challenge when severity of OSA alone is taken into account.

Notably, the literature indicates that not only are many individuals with OSA not sleepy, but also that fatigue is another very common symptom associated with OSA (73). In 2008, Bailes et al. (74) identified four subgroups among individuals with OSA characterized by combinations of high and low levels of daytime fatigue and daytime sleepiness. Of particular interest are those individuals who experienced high fatigue scores, with and without high sleepiness scores. This configuration was associated with the most negative consequences for daytime performance, such as problematic perceived health-related and psychological functioning (74). Of equal interest was the substantial number of individuals with relatively low daytime sleepiness and fatigue scores (i.e. below clinical cut-offs) who, despite an unmistakable OSA diagnosis, appeared not to complain of diminished functioning or quality of life, and to be similar to individuals in a healthy comparison group (4). Much of the literature does not make the distinction between fatigue and sleepiness (ex.: (42) and common language generally confounds the two constructs, e.g. by applying the word "tired" to one or the other.

Another research stream has focused on exogenous, task-induced factors that interact with endogenous characteristics to produce drowsiness and diminish driving performance. For example, time-on-task and time-of-day effects have been associated with fatigue and deterioration of driving performance (75-77). Similarly, the impact of a monotonous, undemanding road environment on driver fatigue and driving errors has been demonstrated in driving simulation studies in which the road environment was varied (e.g., (77)). 
Most of the literature on driving behavior in patients with OSA refers to sleepiness behind the wheel, nodding off, near-miss road accidents, actual road accidents and cognitive impairment. No studies were found addressing driving offenses in non-commercial drivers with OSA (e.g. where commercial drivers were specifically excluded $(78,79))$. Further research is needed to compare self-reported driving offenses and official driving records among non-commercial drivers, with and without OSA, and to examine how risky driving behaviours among non-commercial drivers compare in these two groups in general, and in groups of individuals with OSA in particular.

\section{Assessing fitness to drive}

The prevalence, burden, and management of sleep disorders are too often ignored or overlooked by patients and clinicians. A contributing factor is that many individuals experiencing daytime sleepiness fail to discuss either night time or daytime sleep-related problems with their physicians $(74,80)$. Because the link between sleep problems and sleep disorders, such as OSA, has not been made, sleep disorders are often under diagnosed and untreated, making this group of illnesses a serious health concern. A recent Australian paper discusses the importance of education and instruction among potentially dangerous drivers (81). They found that unsafe drivers are likely to withhold from their physicians information that could potentially lead to an OSA diagnosis if they thought that the medical condition could jeopardize their driver's license. Results of that study found that more unsafe drivers will self-report to the authorities with education and encouragement to do so (81).

A number of studies show that among primarily commercial drivers, OSA often impairs driving performance and increases the risk of being involved in an accident (82). Recently, a study looked at data from the very first large-scale, employer-mandated program to screen, diagnose, and monitor OSA treatment adherence in the US trucking industry. The American paper found that commercial drivers with OSA who were not 
adherent to CPAP treatment had a fivefold increase in the risk of preventable heavy truck crashes compared to matched controls (83).

Moreover, after successful treatment, drivers with OSA had similar crash risk rates as those of controls. More importantly, truck drivers who refused treatment were decommissioned by the mandated employer, but likely found employment elsewhere (83).

For non-commercial drivers, driving is also an essential part of everyday life and a licence to drive plays an important role in social functioning (i.e. employment). Current practice for giving advice to individuals with OSA is to link severity of OSA with sleepiness scores (i.e. Epworth Sleepiness Scale) in assessing driving risk (84). A Swedish large-scale cohort study found that age, driving distance, sleepiness score (ESS), short habitual sleep time and the use of hypnotics are associated with increased road accidents, and that severity of OSA was poorly associated with road accidents among non-commercial drivers (85). Furthermore, their data showed that whether they had a history of road accidents prior to OSA diagnosis or not, the severity of OSA was similar (85).

The literature notwithstanding, clinicians tend to base their decisions on historical and behavioural self-report. Road testing is not feasible for assessing fitness to drive because it is time consuming, expensive, and potentially hazardous (86). Driving simulators are very expensive and not widely available (86). An office-based driving simulator task could potentially aid in a clinician's decision-making when assessing driving risk (87), but this may also not be feasible for most practitioners. In 2013, a group of researchers carried out a study where 118 patients, newly diagnosed with sleep apnea, completed a questionnaire about their driving behaviour and undertook a driving test on the simulator. Nodding at the wheel was admitted by 35 percent but subsequently only 38 percent of those who nodded at the wheel failed the driving simulation task (i.e. crash). This suggested that the experimental driving test has poor ecological validity (84). Clearly, the question of how to develop more accurate and expedient measures to assess driving risk is complex and needs to take into account more than daytime sleepiness or the presence and severity 
of a sleep disorder. Concomitant factors such as medication use and chronic illnesses should also be considered when assessing driving risk (8893).

\section{Practice Points}

Clinical guidelines for risky driving prediction in non-commercial drivers with Obstructive sleep apnea guidelines may include:

1. Discussing night time or daytime sleep-related problems with their patients (including total sleep time and waking after sleep onset);

2. Assessing patients' driving habits (i.e. driving distances);

3. Considering concomitant factors such as medication use and chronic illnesses that may influence their patients' driving performances.

\section{Conclusions}

There is a lack of uniformity from different consensus and Guidelines as to how to deal with the issue of driving by individuals with OSA .Clear guidelines are limited and few are evidence based. Even if recommendations were to be based on existing research, the conclusions from various studies were often inconsistent. For example, some suggested that there be some sort of cut-off in terms of sleep apnea severity to 
remove untreated OSA patients off the road in order to reduce, but not eliminate the risk completely, of road accidents involving OSA patients. Others suggested that it was unclear which aspect of OSA was the most accurate severity measure, e.g. fragmented sleep vs oxygenation (5, 94). There are at least two major difficulties for the driving recommendation process; (a) there is no accurate metric quantifying severity of driving risk associated with OSA, and (b) studies have demonstrated substantial experiential and behavioural individual differences among patients with OSA (cf. (56)).

Sleepiness while driving is undoubtedly a key issue, but, again, there exists a range of contextual complexities. Fatigue remains a term to be differentiated from sleepiness in both the literature and clinical practices/guidelines. Certainly, this review suggests that excessive daytime sleepiness (which could itself be due either to structural brain changes or to transient, context-related states) is not the only potential risk engendered by untreated OSA.

\section{Implications for future research directions}

It is acknowledged that OSA is very common in the adult population worldwide and that individuals with OSA who are not being diagnosed and treated are at an increased risk of dangerous driving. Fatal car crashes provide a strong rationale for advancing driving safety research.

Nevertheless, developing a set of guidelines for drivers with OSA remains a challenge since it is still unclear which aspects of OSA is associated to risky driving among non-commercial drivers. To develop comprehensive evidence-based recommendations to guide policy decisions, future research directions could include: 
1. Identify and differentiate which aspects of driving risk are due to cognitive and sensorimotor deficits caused by OSA-related changes in brain structure and which are due to transient somnolence and/or fatigue states among non-commercial drivers. One would also need to examine the modifying role of context for both these aspects. Furthermore, there is only speculation, but little data on whether structural brain changes that have been associated with OSA in fact cause particular types of driver error.

2. Develop a better understanding of the interaction between OSA and its comorbidities (i.e. the metabolic syndrome components of hypertension, diabetes, and obesity) that may, themselves, lead to brain pathology and altered driving performance.

3. Conceptualize driving risk as a constellation of symptoms along with their severity or impact. A better understanding of experiential and contextual factors (ex.: cultural context) and how these may be related to driving behaviors and risk assessment in people diagnosed with OSA, could be helpful in developing profiles of driving risk in individuals with OSA. Accurate risk profiles would also provide the basis for developing techniques to manage driving risk, so that evaluations of driving risk could include recommendations of techniques to improve driving safety.

\section{Research Agenda}

In the future we need to be able to not only to identify patients with Obstructive sleep apnea, but to also assess:

1. Which patients are exposed to risky driving due to sensorimotor deficits caused by Obstructive sleep apnea-related changes in brain structure;

2. Which patients are at higher risk of morbidity, possibly leading to poorer driving performances;

3. A profile of driving risk to provide patients with a list of recommendations specific to 


\section{REFERENCES}

1. Peppard PE, Young, T., Barnet, J.H., Palta, M., Hagen, E.W., Hla KM. Increased prevalence of sleep-disordered breathing in adults. American Journal of Epidemioly, 177(9). 2013:1006.

2. Punjabi NM. The epidemiology of adult obstructive sleep apnea. Proceedings of the American Thoracic Society. $2008 ; 5(2): 136-43$.

3. Peppard PE, Young T, Barnet JH, Palta M, Hagen EW, Hla KM. Increased prevalence of sleep-disordered breathing in adults. American journal of epidemiology. 2013;177(9):1006-14.

4. Bailes S, Libman E, Baltzan M, Grad R, Kassissia I, Creti L, et al. Fatigue: the forgotten symptom of sleep apnea. Journal of psychosomatic research. 2011;70(4):346-54.

5. Bucks RS, Olaithe M, Eastwood P. Neurocognitive function in obstructive sleep apnoea: A meta-review. Respirology. 2013;18(1):61-70.

6. Gagnon K, Baril A-A, Gagnon J-F, Fortin M, Decary A, Lafond C, et al. Cognitive impairment in obstructive sleep apnea. Pathologie Biologie. 2014;62(5):233-40.

7. Nishino S, Riehl J, Hong J, Kwan M, Reid M, Mignot E. Is narcolepsy a REM sleep disorder? Analysis of sleep abnormalities in narcoleptic Dobermans. Neuroscience research. 2000;38(4):437-46.

8. Ford ES, Cunningham TJ, Croft JB. Trends in self-reported sleep duration among US adults from 1985 to 2012 . Sleep. $2015 ; 38(5): 829-32$.

9. Rodenstein D. Driving in Europe: the need of a common policy for drivers with obstructive sleep apnoea syndrome. Journal of sleep research. 2008;17(3):281-4

10. Weaver TE, Maislin G, Dinges DF, Bloxham T, George CF, Greenberg H, et al. Relationship between hours of CPAP use and achieving normal levels of sleepiness and daily functioning. SLEEP-NEW YORK THEN WESTCHESTER-. 2007;30(6):711.

11. Lyznicki JM, Doege TC, Davis RM, Williams MA. Sleepiness, driving, and motor vehicle crashes. Jama. 1998;279(23):1908-13.

12. Franklin KA, Lindberg E. Obstructive sleep apnea is a common disorder in the population-a review on the epidemiology of sleep apnea. Journal of thoracic disease. 2015;7(8):1311.

13. Patterson KC, Huang F, Oldham JM, Bhardwaj N, Hogarth DK, Mokhlesi B. Excessive daytime sleepiness and obstructive sleep apnea in patients with sarcoidosis. CHEST Journal. 2013;143(6):1562-8.

14. Sforza E, Roche F. Sleep apnea syndrome and cognition. Sleep and cognition in the elderly. 2015:49.

15. Day R, Gerhardstein R, Lumley A, Roth T, Rosenthal L. The behavioral morbidity of obstructive sleep apnea. Progress in cardiovascular diseases. 1999;41(5):341-54.

16. Eckert DJ, Malhotra A, Lo YL, White DP, Jordan AS. The influence of obstructive sleep apnea and gender on genioglossus activity during rapid eye movement sleep. CHEST Journal. 2009;135(4):957-64.

17. Eckert DJ, Butler, J.E. Respiratory Physiology: Understanding the Control of Ventilation. Principles and Practice of Sleep Medicine. Philadelphia, PA: Elsevier; 2016. p. 167-73.

18. Dewan NA, Nieto FJ, Somers VK. Intermittent hypoxemia and OSA: implications for comorbidities. CHEST Journal. 2015;147(1):266-74.

19. Chasens ER. Obstructive sleep apnea, daytime sleepiness, and type 2 diabetes. The Diabetes Educator. 2007;33(3):475-82.

20. Marshall NS, Wong K, Cullen S, Knuiman MW, Grunstein RR. Sleep apnea and 20-year follow-up for all-cause mortality, stroke, and cancer incidence and mortality in the Busselton Health Study cohort. J Clin Sleep Med. 2014;10(4):355-62. 
21. Cowie MR, Woehrle H, Wegscheider K, Angermann C, d'Ortho M-P, Erdmann E, et al. Adaptive servo-ventilation for central sleep apnea in systolic heart failure. New England Journal of Medicine. 2015;373(12):1095-105.

22. Eckert DJ, Malhotra A, Jordan AS. Mechanisms of apnea. Progress in cardiovascular diseases. 2009;51(4):313-23.

23. School HM. Abdominal fat and what to do about it: Harvard Health Publications; 2015 [cited 2016 May 4, 2016]. Available from: http://www.health.harvard.edu/fhg/updates/Abdominal-fat-and-what-to-do-about-it.shtml.

24. Korcarz CE, Stein JH, Peppard PE, Young TB, Barnet JH, Nieto FJ. Combined effects of sleep disordered breathing and metabolic syndrome on endothelial function: the Wisconsin Sleep Cohort study. Sleep. 2014;37(10):1707.

25. Reutrakul S, Van Cauter E. Interactions between sleep, circadian function, and glucose metabolism: implications for risk and severity of diabetes. Annals of the New York Academy of Sciences. 2014;1311(1):151-73.

26. Chiu HK, Tsai EC, Juneja R, Stoever J, Brooks-Worrell B, Goel A, et al. Equivalent insulin resistance in latent autoimmune diabetes in adults (LADA) and type 2 diabetic patients. Diabetes research and clinical practice. 2007;77(2):237-44.

27. Louis M, Punjabi NM. Effects of acute intermittent hypoxia on glucose metabolism in awake healthy volunteers. Journal of applied physiology. 2009;106(5):1538-44.

28. Cappuccio FP, D'Elia L, Strazzullo P, Miller MA. Sleep duration and all-cause mortality: a systematic review and meta-analysis of prospective studies. Sleep. 2010;33(5):585.

29. Broussard JL, Ehrmann DA, Van Cauter E, Tasali E, Brady MJ. Impaired insulin signaling in human adipocytes after experimental sleep restriction: a randomized, crossover study. Annals of internal medicine. 2012;157(8):549-57.

30. Balkau B, Loko S, Andriamboavonjy T, Lantieri O, Gusto G, Meslier N, et al. High baseline insulin levels associated with 6-year incident observed sleep apnea. Diabetes Care. 2010;33(5):1044-9.

*31. Vgontzas AN, Bixler EO, Chrousos GP. Sleep apnea is a manifestation of the metabolic syndrome. Sleep medicine reviews. 2005;9(3):21124.

32. Coughlin SR, Mawdsley L, Mugarza JA, Calverley PM, Wilding JP. Obstructive sleep apnoea is independently associated with an increased prevalence of metabolic syndrome. European heart journal. 2004;25(9):735-41.

33. Badran M, Yassin BA, Fox N, Laher I, Ayas N. Epidemiology of sleep disturbances and cardiovascular consequences. Canadian journal of cardiology. 2015;31(7):873-9.

*34. O'Donoghue FJ, Wellard RM, Rochford PD, Dawson A, Barnes M, Ruehland WR, et al. Magnetic resonance spectroscopy and neurocognitive dysfunction in obstructive sleep apnea before and after CPAP treatment. Sleep. 2012;35(1):41-8.

35. Flemons WW, Remmers JE, Whitelaw WA. The correlation of a computer simulated driving program with polysomnographic indices and neuropsychological tests in consecutively referred patients for assessment of sleep apnea. Sleep: Journal of Sleep Research \& Sleep Medicine. 1993.

36. McKay A, Liew C, Schönberger M, Ross P, Ponsford J. Predictors of the On-Road Driving Assessment After Traumatic Brain Injury: Comparing Cognitive Tests, Injury Factors, and Demographics. The Journal of head trauma rehabilitation. 2015.

*37. Kim HC, Young T, Matthews CG, Weber SM, Woodard AR, Palta M. Sleep-disordered breathing and neuropsychological deficits: a population-based study. American journal of respiratory and critical care medicine. 1997;156(6):1813-9. 
38. Ayalon L, Ancoli-Israel S, Aka AA, McKenna BS, Drummond S. Relationship between obstructive sleep apnea severity and brain activation during a sustained attention task. Sleep. 2009;32(3):373-81.

39. Maya JF, Portera, B.E., Ware, J.C. The deterioration of driving performance over time in drivers with untreated sleep apnea. Accident Analysis \& Prevention. 2016;89:96-102.

*40. Vakulin A, D’Rozario, A., Kim, J.-W., Watson., B., Cross, N., Wang, D., Coeytaux, A., Bartlett, D., Wong, K., Grunstein, R. Quantitative sleep EEG and polysomnographic predictors of driving simulator performance in obstructive sleep apnea. Clinical Neurophysiology. 2016;127(2):142835.

41. Vakulin A, Dorrian J, Duggan TR, Litchfield CA, Cobb KJ, Antic NA, et al. Behavioural Observation as a Means of Assessing Sleepiness Related Driving Impairment in Obstructive Sleep Apnea. Eat, Sleep, Work. 2015.

42. Aksan N, Dawson J, Tippin J, Lee JD, Rizzo M, editors. Effects of fatigue on real-world driving in diseased and control participants. Proceedings of the International Driving Symposium on Human Factors in Driver Assessment, Training, and Vehicle Design; 2015: NIH Public Access.

*43. Vakulin A. Driving Impairment and Accident Risk in Sleep Apnea: We Need Better Assessment Tools. Sleep Disorders: Treatment and Care. 2015;2012.

44. Rizzo D, Lavigne G, Creti L, Bergeron J, Baltzan M, Tran D, et al. Are drivers with OSA getting bad press? Sleep Medicine. 2015;16:S246. 45. Ayas NT, Hirsch AA, Laher I, Bradley TD, Malhotra A, Polotsky VY, et al. New frontiers in obstructive sleep apnoea. Clinical Science. 2014;127(4):209-16.

46. Strohl KP, Saunders NA, Feldman NT, Hallett M. Obstructive sleep apnea in family members. New England Journal of Medicine. 1978;299(18):969-73.

47. Ayas N, Skomro, R., Blackman, A., Curren, K., Fitzpatrick, M., Fleetham, J., George, C., Hakemi, T., Hanly, P., Li, C., Morrison, D., Series, F. Obstructive sleep apnea and driving: A Canadian Thoracic Society and Canadian Sleep Society position paper. Can Respiratory Journal, 21(2):11423. 2014.

48. Strohl KP, Brown, D.B., Collop, N., George, C., Grunstein, R., Han, F., Kline, L., Malhotra., A., Pack, A., Phillips., B., Rodenstein, D., Schwab., R., Weaver., T., Wilson, K. An official American Thoracic Society Clinical Practice Guideline: Sleep Apnea, Sleepiness, and Driving Risk in Noncommercial drivers. Amercian Journal of Repiratory and Critical Care Medicine. 2013;187(11):1259-66.

49. McNicholas WT. New Standards and Guidelines for Drivers with Obstructive Sleep Apnoea syndrome-Report of the Obstructive Sleep Apnoea Working Group. European Commission. Directorate-General for Energy and Transport, 2013.

50. Strohl KP, Brown DB, Collop N, George C, Grunstein R, Han F, et al. An official American Thoracic Society Clinical Practice Guideline: sleep apnea, sleepiness, and driving risk in noncommercial drivers. An update of a 1994 Statement. American journal of respiratory and critical care medicine. 2013;187(11):1259-66.

51. McNicholas W. New Standards and Guidelines for. Brussels: Obstructive Sleep Apnoea Working Group, 2013.

52. Ruskin KJ, Caldwell, J.A., Caldwell, L., Boudreau, E.A. Screening for Sleep Apnea in Morbidly Obese Pilots. Aerospace Medicine and Human Performance. 2015. 
*53. Gonçalves M, Amici R, Lucas R, Åkerstedt T, Cirignotta F, Horne J, et al. Sleepiness at the wheel across Europe: a survey of 19 countries. Journal of sleep research. 2015;24(3):242-53.

54. Admnistration NHS. Fatality analysis reporting system encyclopedia: NCSA Data Reseource Website; 2013 [cited 2016 May 30, 2016]. Available from: http://www-fars.nhtsa.dot.gov/Main/index.aspx.

55. Siskind V, Steinhardt D, Sheehan M, O’Connor T, Hanks H. Risk factors for fatal crashes in rural Australia. Accident Analysis \& Prevention. 2011;43(3):1082-8.

*56. Vakulin A, Catcheside PG, Baulk SD, Antic NA, Banks S, Dorrian J, et al. Individual variability and predictors of driving simulator impairment in patients with obstructive sleep apnea. J Clin Sleep Med. 2014;10(6):647-55.

57. Ward KL, Hillman DR, James A, Bremner AP, Simpson L, Cooper MN, et al. Excessive daytime sleepiness increases the risk of motor vehicle crash in obstructive sleep apnea. Journal of clinical sleep medicine: JCSM: official publication of the American Academy of Sleep Medicine. 2013;9(10):1013.

58. Daltro C, Gregorio, P.B., Alves, E., Abreu, M., Bomfim, D. Prevalence and severity of sleep apnea in a group of morbidly obese patients. Obesity Surgery. 2007.

59. Teran-Santos J, Jimenez-Gomez A, Cordero-Guevara J. The association between sleep apnea and the risk of traffic accidents. New England Journal of Medicine. 1999;340(11):847-51.

60. Kay GG, McLaughlin D. Relationship between obesity and driving. Current obesity reports. 2014;3(3):336-40.

61. Kay GG, McLaughlin, D. Relationship between obesity and driving. Curr Obes Rep, 3, 336-340. 2014.

62. Basoglu OK, Tasbakan, M.S. Elevated Risk of Sleepiness-RelatedMotor Vehicle Accidents in Patients With Obstructive Sleep Apnea Syndrome: A case control study. Traffic Injury Prevention, 15, 470-476. 2014.

63. Katz SL, Vaccani, J.P., Barrowman, N., Momoli, F., Bradbury, C.L., Murto, K. Does neck-to-waist ratio predict obstructive sleep apnea in children? Journal of Clinical Sleep Medicine. 2014;10(12):1303-8.

64. Peromaa-Haavisto P, Tuomilehto, H., Kössi, J., Virtanen, J., Luostarinen, M., Pihlajamäki, J., Käkelä, P., Victorzon, M. Prevalence of Obstructive Sleep Apnoea Among Patients Admitted for Bariatric Surgery. A Prospective Multicentre Trial. Obesity and Surgery. 2015.

65. Ho AW, Moul, D.E., Krishna, J. Neck Circumference-Height Ratio as a Predictor of Sleep Related Breathing Disorder in Children and Adults. Journal of Clinical Sleep Medicine. 2015.

66. Gunstad J, Strain G, Devlin MJ, Wing R, Cohen RA, Paul RH, et al. Improved memory function 12 weeks after bariatric surgery. Surgery for Obesity and Related Diseases. 2011;7(4):465-72.

67. Gunstad J, Strain, G., Devlin, M.J., Wing, R., Cohen, R.A., Paul, R.H., Crosby, R.D., Mitchell, J.E. Improved Memory Function 12 Weeks after Bariatric Surgery. Surgery for Obesity and Related Diseases. 2011;7(4):465-72.

68. Sarkhosh K, Switzer NJ, El-Hadi M, Birch DW, Shi X, Karmali S. The impact of bariatric surgery on obstructive sleep apnea: a systematic review. Obesity surgery. 2013;23(3):414-23.

69. Redenius R, Murphy, C., O'Neill, E.O., al-Hamwi, M., Zallek, S.N. Does CPAP lead to BMI? Journal of Clinical Sleep Medicine 2008.

70. Sarkhosh K, Switzer, N.J., El-Hadi, M., Birch, D.W., Shi, X., Karmali, S. The impact of bariatric surgery on obstructive sleep apnea: a systematic review. Obesity and Surgery 2013:414-23. 
71. Pack Al, Maislin G, Staley B, Pack FM, Rogers WC, George CFP, et al. Impaired performance in commercial drivers: role of sleep apnea and short sleep duration. American journal of respiratory and critical care medicine. 2006;174(4):446-54.

*72. Czeisler CA, Wickwire EM, Barger LK, Dement WC, Gamble K, Hartenbaum N, et al. Sleep-deprived motor vehicle operators are unfit to drive: a multidisciplinary expert consensus statement on drowsy driving. Sleep Health. 2016;2(2):94-9.

73. Hossain JL, Shapiro CM. The prevalence, cost implications, and management of sleep disorders: an overview. Sleep and Breathing. 2002;6(02):085-102.

74. Bailes S, Baltzan M, Rizzo D, Fichten CS, Amsel R, Libman E. A diagnostic symptom profile for sleep disorder in primary care patients. J Psychosom Res. 2008;64(4):427-33.

75. Pack AI, Pack AM, Rodgman E, Cucchiara A, Dinges DF, Schwab CW. Characteristics of crashes attributed to the driver having fallen asleep. Accident Analysis \& Prevention. 1995;27(6):769-75.

76. Smiley A, editor Fatigue management: lessons from research. INTERNATIONAL CONFERENCE ON FATIGUE AND TRANSPORTATION, 3RD, 1998, FREMANTLE, WESTERN AUSTRALIA; 1998.

77. Thiffault $P$, Bergeron J. Fatigue and individual differences in monotonous simulated driving. Personality and Individual Differences. 2003;34(1):159-76.

78. Bioulac S, Tailard J, Quera-Salva M-A, Sagaspe P, Philip P, editors. Attention deficit hyperactivity symptoms, sleepiness and near-misses driving accidents among a population of French highway drivers. JOURNAL OF SLEEP RESEARCH; 2014: WILEY-BLACKWELL 111 RIVER ST, HOBOKEN 07030-5774, NJ USA.

79. Sagaspe P, Taillard J, Bayon V, Lagarde E, Moore N, Boussuge J, et al. Sleepiness, near-misses and driving accidents among a representative population of French drivers. Journal of sleep research. 2010;19(4):578-84.

80. Sánchez Al, Martínez P, Miró E, Bardwell WA, Buela-Casal G. CPAP and behavioral therapies in patients with obstructive sleep apnea: effects on daytime sleepiness, mood, and cognitive function. Sleep medicine reviews. 2009;13(3):223-33.

81. Elgar NJ, Esterman AJ, Antic NA, Smith BJ. Self-Reporting by Unsafe Drivers Is, with Education, More Effective than Mandatory Reporting by Doctors. Journal of clinical sleep medicine: JCSM: official publication of the American Academy of Sleep Medicine. 2014;12(3):293-9.

82. Tregear S, Reston J, Schoelles K, Phillips B. Obstructive sleep apnea and risk of motor vehicle crash: systematic review and meta-analysis. J Clin Sleep Med. 2009;5(6):573-81.

83. Burks SV, Anderson JE, Bombyk M, Haider R, Ganzhorn D, Jiao X, et al. Nonadherence with Employer-Mandated Sleep Apnea Treatment and Increased Risk of Serious Truck Crashes. Sleep. 2015;39(5):967-75.

84. Elliott MW, editor How to predict the risk of traffic accidents in sleepy patients. Sleep and Breathing; 2013; Berlin, Germany.

*85. Karimi M, Hedner J, Zou D, Eskandari D, Lundquist A-C, Grote L. Attention deficits detected in cognitive tests differentiate between sleep apnea patients with or without a motor vehicle accident. Sleep medicine. 2015;16(4):528-33.

86. Turkington PM, Sircar M, Allgar V, Elliott MW. Relationship between obstructive sleep apnoea, driving simulator performance, and risk of road traffic accidents. Thorax. 2001;56(10):800-5.

87. Ghosh D, Jamson SL, Baxter PD, Elliott MW. Continuous measures of driving performance on an advanced office-based driving simulator can be used to predict simulator task failure in patients with obstructive sleep apnoea syndrome. Thorax. 2012:thoraxjnl-2011-200699. 
88. Asbridge M, Cartwright, J., Langille, D. Driving under the influence of opioids among high school students in Atlantic Canada: prevalence, correlates, and the role of medical versus recreational consumption. Accident; analysis and prevention. 2015;75:184-91.

*89. Philip P, Micoulaud-Franchi, J.A., Lagarde, E., Taillard, J., Canel, A., Sagaspe, P., Bioulac, S. Attention Deficit Hyperactivity Disorder Symptoms, Sleepiness and Accidental Risk in 36140 Regularly Registered Highway Drivers. PLoS One. 2015;10(9).

90. Bioulac S, Chaufton, C., Taillard, J., Claret, A., Sagaspe, P., Fabrigoule, C., Bouvard, M.P., Philip, P. Excessive daytime sleepiness in adult patients with ADHD as measured by the Maintenance of Wakefulness Test, an electrophysiologic measure. Journal of Clinical Psychiatry. 2015;76(7):943-8.

91. Orriols L, Avalos-Fernandez, M., Moore, N., Philip, P., Delorme, B., Laumon, B., Gadegbeku, B., Salmi, L.R., Lagarde, E. Long-term chronic diseases and crash responsibility: a record linkage study. Accident; analysis and prevention. 2014;71:137-43.

92. Moták L, Bayssac, L., Taillard, J., Sagaspe, P., Huet, N., Terrier, P., Philip, P., Daurat, A. Naturalistic conversation improves daytime motorway driving performance under a benzodiazepine: a randomised, crossover, double-blind, placebo-controlled study. Accident; analysis and prevention. 2014;67:61-6.

93. Philip P, Chaufton, C., Taillard, J., Capelli, A., Coste, O., Léger, D., Moore, N., Sagaspe, P. Modafinil improves real driving performance in patients with hypersomnia: a randomized double-blind placebo-controlled crossover clinical trial. Sleep. 2014;37(3):483-7.

94. George CF. Sleep apnea, alertness, and motor vehicle crashes. American journal of respiratory and critical care medicine. 2007;176(10):954-6. 
Table 1

Current driving policies developed and adopted by leading countries in driving research.

\begin{tabular}{|c|c|c|}
\hline Country & National Driving Policies & Research influencing policy-making \\
\hline Australia & $\begin{array}{l}\text { A person is not fit to hold an unconditional licence if }{ }^{\text {: }} \\
\text { (1) the person has OSA (on a diagnostic sleep study and } \\
\text { moderate to severe excessive daytime sleepiness), or; } \\
\text { (2) the person has frequent self-reported episodes of } \\
\text { sleepiness or drowsiness while driving, or; (3) the person } \\
\text { has had motor vehicle crash/es caused by inattention or } \\
\text { sleepiness, or; (4) the person, in opinion of the treating } \\
\text { doctor, represents a significant driving risk as a result of } \\
\text { a sleep disorder. } \\
\text { A conditional licence may be considered by the driver } \\
\text { licensing authority subject to periodic review, taking into } \\
\text { account the nature of the driving task and information } \\
\text { provided by the treating doctor as to whether the } \\
\text { following criteria are met }{ }^{1} \text { : the person is compliant with } \\
\text { treatment; and the response to treatment is satisfactory }\end{array}$ & $\begin{array}{l}\text { Howard, M. E., Jackson, M. L., \& Stevenson, M. (2015). Who Needs Sleep } \\
\text { Apnea Treatment for Safety Critical Tasks-Are We There } \\
\text { Yet?. Sleep,38(3), } 331 . \\
\text { Vakulin, A., Catcheside, P. G., Baulk, S. D., Antic, N. A., Banks, S., } \\
\text { Dorrian, J., \& McEvoy, R. D. (2014). Individual variability and predictors } \\
\text { of driving simulator impairment in patients with obstructive sleep } \\
\text { apnea. J Clin Sleep Med, 10(6), 647-55. } \\
\text { Vakulin, A., D’Rozario, A. L., \& Grunstein, R. R. (2012). Driving Impairment } \\
\text { and Accident Risk in Sleep Apnea: We Need Better Assessment Tools. } \\
\text { J Sleep Disor: Treat Care 1: 1. of, 2, 2. } \\
\text { Desai, A. V., Wilsmore, B., Bartlett, D. J., Unger, G., Constable, B., Joffe, } \\
\text { D., \& Grunstein, R. R. (2007). The utility of the AusEd driving simulator } \\
\text { in the clinical assessment of driver fatigue. Behavior research } \\
\text { methods, 39(3), 673-681. }\end{array}$ \\
\hline Belgium & A person with OSA who experiences sleepiness is unfit & McNicholas, W. T., \& Rodenstein, D. (2015). Sleep apnoea and driving \\
\hline
\end{tabular}




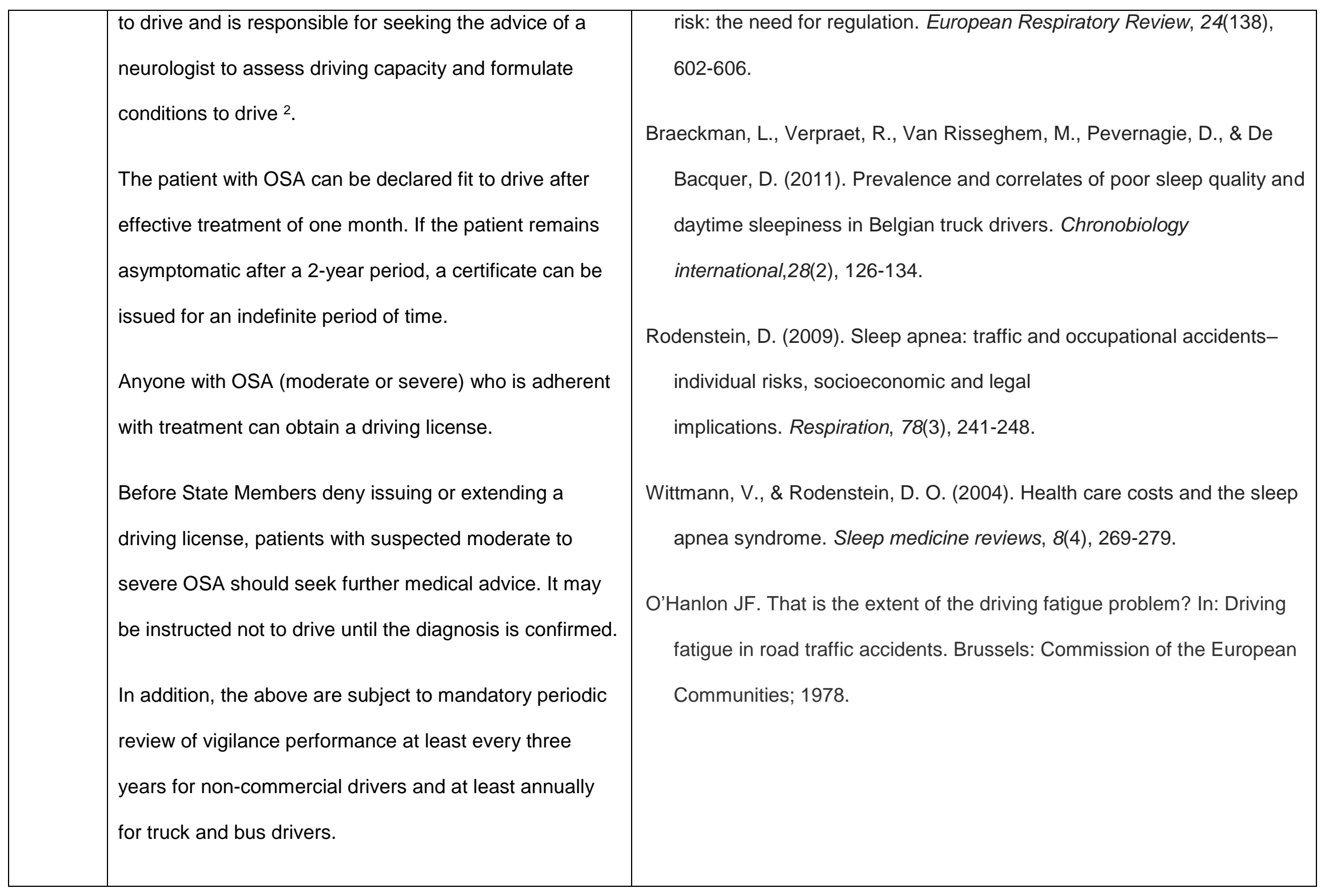




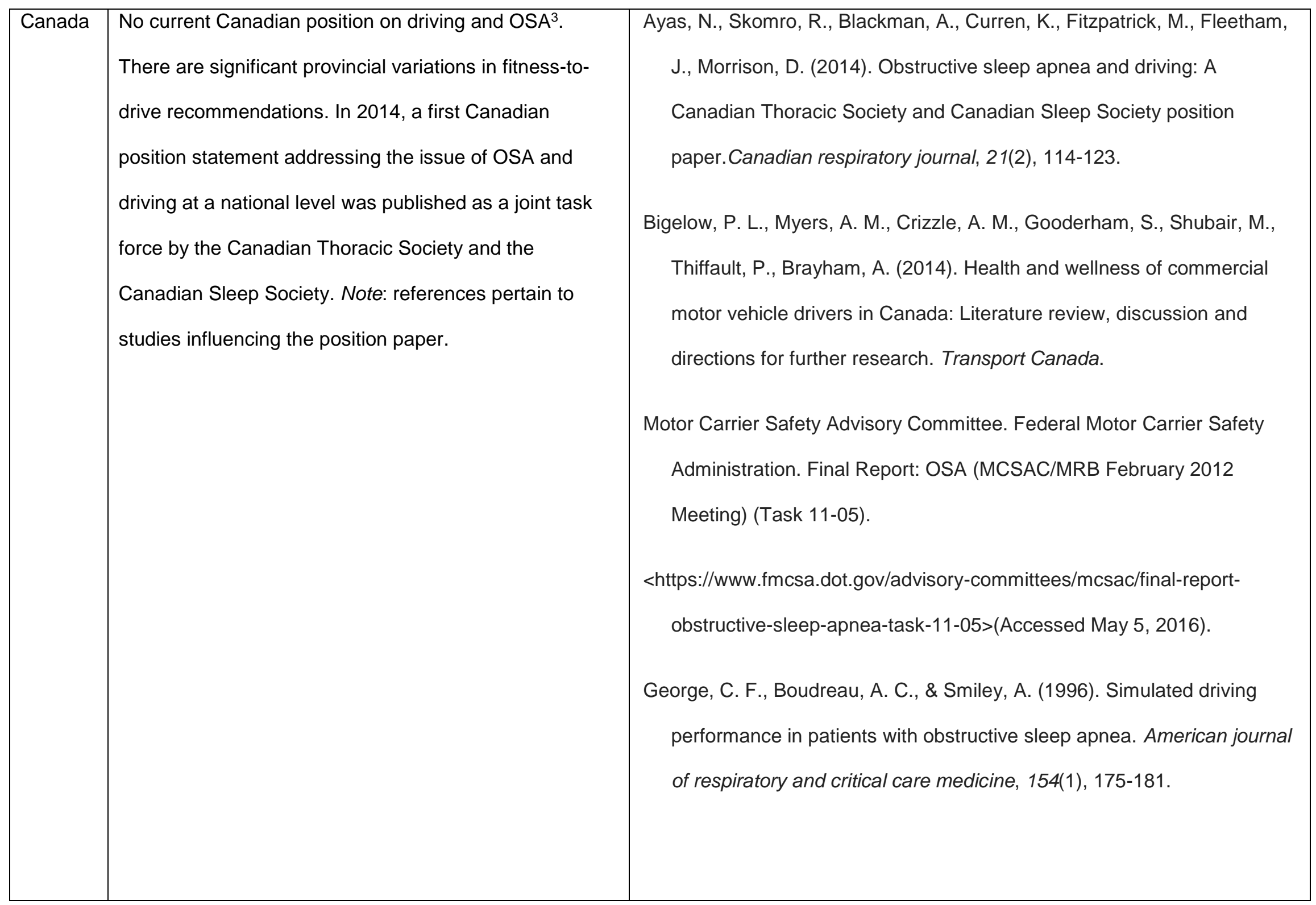




\begin{tabular}{|c|c|c|}
\hline France & $\begin{array}{l}\text { OSA is a medical condition likely incompatible with } \\
\text { obtaining, maintaining or may lead to the issuing of a } \\
\text { limited driver's license }{ }^{4} \text {. } \\
\text { A driver's license should not be granted or renewed for } \\
\text { applicants or drivers suffering from a condition } \\
\text { associated with functional disability and are a risk to road } \\
\text { safety. The decision to issue or renew a license is made } \\
\text { following a review of the Medical Commissions } \\
\text { Department or a licensed physician. These bodies are } \\
\text { entitled to add conditions and restrictions on driving } \\
\text { licenses or to request information to better assess the } \\
\text { risk. } \\
\text { Prior to each medical examination, the driver must } \\
\text { provide an accurate description of medical history, any } \\
\text { current pathology and any medications taken. } \\
\text { A test conducted by a driving school may be requested. } \\
\text { The medical officer or the medical committee may, after } \\
\text { initial examination and if they consider it appropriate, }\end{array}$ & $\begin{array}{l}\text { Äkerstedt, T., \& Philip, P. (2015). Sleep Disorders, Cognition, Accidents, } \\
\text { and Performance. In Sleep Medicine (pp. 487-494). Springer New York. } \\
\text { Philip, P., Sagaspe, P., Lagarde, E., Leger, D., Ohayon, M. M., Bioulac, B., } \\
\text { Taillard, J. (2010). Sleep disorders and accidental risk in a large group } \\
\text { of regular registered highway drivers. Sleep medicine, 11(10), 973-979. }\end{array}$ \\
\hline
\end{tabular}




\begin{tabular}{|c|c|c|}
\hline & e Appeal Medical Board. & \\
\hline USA & $\begin{array}{l}\text { No current U.S. position on driving and OSA. Each U.S. } \\
\text { state sets its own medical standards for non-commercial } \\
\text { drivers. National Highway Traffic Safety Administration } \\
\text { regulations do not specifically address OSA. The } \\
\text { recommendations regarding licensure are likely to be } \\
\text { based on an inadequate research data, therefore more } \\
\text { studies are required } 5 \text {. } \\
\text { For commercial motor vehicle drivers, regulations state } \\
\text { that a person with a medical history or clinical diagnosis } \\
\text { of any condition likely to interfere with their ability to drive } \\
\text { safely cannot be medically qualified to operate a vehicle } \\
\text { in interstate commerce (OSA is not specifically } \\
\text { addressed). The Federal Motor Carrier Safety } \\
\text { Association recommends that when a person is } \\
\text { diagnosed with OSA, he/she should (1) contact the } \\
\text { medical qualifying examiner to determine his/her fitness } \\
\text { to operate a commercial motor vehicle and to be advised } \\
\text { on treatment, ( } 2 \text { ) be qualified by the medical examiner to }\end{array}$ & $\begin{array}{l}\text { Mukherjee, S., Patel, S. R., Kales, S. N., Ayas, N. T., Strohl, K. P., Gozal, } \\
\text { D., \& Malhotra, A. (2015). An official American Thoracic Society } \\
\text { statement: the importance of healthy sleep. Recommendations and } \\
\text { future priorities.American journal of respiratory and critical care } \\
\text { medicine, 191(12), 1450-1458. } \\
\text { Colvin, L. J., \& Collop, N. A. (2015). Commercial Motor Vehicle Driver } \\
\text { Obstructive Sleep Apnea Screening and Treatment in the United } \\
\text { States: An Update and Recommendation Overview. Journal of clinical } \\
\text { sleep medicine: JCSM: official publication of the American Academy of } \\
\text { Sleep Medicine,12(1), 113-125. } \\
\text { Kay, G. G., \& McLaughlin, D. (2014). Relationship between obesity and } \\
\text { driving. Current obesity reports, 3(3), 336-340. } \\
\text { Lal, C., Strange, C., \& Bachman, D. (2012). Neurocognitive impairment in } \\
\text { obstructive sleep apnea. CHEST Journal, 141(6), 1601-1610. } \\
\text { Steinberg, C. (2002). A study of prevalence of sleep apnea among } \\
\text { commercial truck drivers (No. FMCSA-RT-02-080). }\end{array}$ \\
\hline
\end{tabular}




\begin{tabular}{|l|l|l|}
\hline $\begin{array}{l}\text { determine a driver's medical fitness for duty (the } \\
\text { disqualifying level of OSA is moderate to severe), and (3) } \\
\text { adhere treatment provided by their doctor }{ }^{6} .\end{array}$ & $\begin{array}{c}\text { Hiestand, D. M., Britz, P., Goldman, M., \& Phillips, B. (2006). Prevalence of } \\
\text { symptoms and risk of sleep apnea in the US population: results from } \\
\text { the national sleep foundation sleep in America 2005 poll. CHEST } \\
\text { Journal, 130(3), 780-786. }\end{array}$ \\
& $\begin{array}{r}\text { Langlois, P. H., Smolensky, M. H., Hsi, B. P., \& Weir, F. W. (1985). } \\
\text { Temporal patterns of reported single-vehicle car and truck accidents in } \\
\text { Texas, USA during 1980-1983. Chronobiology International, 2(2), 131- } \\
140 .\end{array}$ \\
&
\end{tabular}

1. Publications Online A. Assessing Fitness to Drive for Commercial and Private Vehicle Drivers. In: Commission NT, editor. Australia; 2014.

2. véhicules Cpléàlcelad. Arrêté royal relatif au permis de conduire. In: Routière IBplS, editor. Normes minimales et attestations concernant l'aptitude physique et psychique à la conduite d'un véhicule à moteur. Brussels, Belgium; 1998.

3. Ayas N, Skomro R, Blackman A, et al. Obstructive sleep apnea and driving: A Canadian Thoracic Society and Canadian Sleep Society position paper. Canadian respiratory journal 2014; 21(2): 114-23.

4. I'intérieur Md. Journal officiel de la République Française. In: Française R, editor. Décrets, arrêtés, circulaires. Paris, France; 2015.

5. Dobbs BM. Medical Conditions and Driving: A Review of the Literature (1960 - 2000): U.S. Department of Transportation, National Highway Traffic Safety Administration, 2005.

6. Administration FMCS. Driving When You Have Sleep Apnea. 2016. https://www.fmcsa.dot.gov/driver-safety/sleep-apnea/driving-when-youhave-sleep-apnea (accessed May 4, 2016. 